\title{
Leis justas e ajustadas no Direito 'indiano': algumas chaves para compreender alguns enunciados normativos integrados a uma cultura jurídica diferente*
}

\author{
Just and adjusted laws on Hispanic American Law: some keys for the understanding of some \\ normative statements integrated to a different legal culture
}

Ezequiel Abásolo**

\begin{abstract}
REFERÊNCIA
ABÁSOLO, Ezequiel. Leis justas e ajustadas no Direito 'indiano': algumas chaves para compreender alguns enunciados normativos integrados a uma cultura jurídica diferente. Revista da Faculdade de Direito da UFRGS, Porto Alegre, n. 47, p. 46-56, dez. 2021. DOI: https://doi.org/10.22456/0104-6594.121035.
\end{abstract}

\section{RESUMO}

Se o que se pretende fazer é História do Direito, resulta necessário deter-se a refletir previamente sobre o que compreende na realidade o direito pretérito. Vale dizer, determinar no que consistiu. Contudo, esse direito do passado - como também o do presente, diga-se de passagem - não se reduz a mera normatividade. Trata-se de algo mais complexo. Definitivamente, expressa uma cultura. Ou seja, o que o âmbito jurídico compreende é um conjunto compartido de conhecimentos, valores, princípios e ideologias que, vinculados ao Direito, imperam numa época e num lugar determinados.

\section{PALAVRAS-CHAVE}

História do Direito. Direito indiano (Hispano-americano). Cultura jurídica. Metodologia jurídica.

\begin{abstract}
If what we intend on doing is Legal History, it is necessary to make a previous reflection on what we really understand to be the former Law - that is, to determine what it consisted of. Nevertheless, that which is past - as is the present one - is not restricted to mere normativity. It's something more intricate. Definitively, it manifests a culture. What the "legal" comprehends is a plot of shared knowledges, values, principles, and ideologies which, when connected to the Law, reigns in a specific time and place.
\end{abstract}

\section{KEYWORDS}

Legal History. Hispanic American Law. Legal culture. Legal methodology.

\section{SUMÁRIO}

1. Introdução; 2. Implicações da presença do ius commune; 3. As leis justas e ajustadas; 4. Conclusão; Fontes; Referências bibliográficas; Dados da publicação.

\footnotetext{
* Texto original em língua espanhola: ABÁSOLO, Ezequiel. Leyes justas y ajustadas en el Derecho Indiano: algunas claves para comprender unos enunciados normativos integrados a una cultura jurídica diferente. Colección de las $1^{a s}$ Jornadas de Historia del Derecho 2021: Período Pre-hispano. Pontificia Universidad Católica Argentina (UCA); Universidad del Norte Santo Tomás de Aquino; Centro de Estudios de Historia Constitucional Argentina de Rosario - 23, 24 y 25 de agosto 2021. Buenos Aires: Universidad Católica Argentina, 2021. 10 p. Disponível em: < https://repositorio.uca.edu.ar/handle/123456789/12436 >. Tradução de Frederico Paganin Gonçalves (aluno de graduação em Ciências Jurídicas e Sociais - Faculdade de Direito, UFRGS). Revisão da tradução por Alfredo de J. Flores (Professor Permanente do PPGDir./UFRGS). Os tradutores agradecem ao autor do presente texto pela autorização da tradução e adaptações necessárias à edição brasileira. Ademais, os tradutores introduziram títulos, que não estão presentes no texto original, às divisões do texto, para efeitos da adaptação às normas brasileiras.

** Doutor em Direito (Universidad de Buenos Aires). Doutor em Ciência Política (Pontificia Universidad Católica Argentina). Professor de História do Direito e de outras áreas afins em várias instituições argentinas (UBA, UCA, Universidad de Morón). Diretor do Instituto de Investigaciones de Historia del Derecho (Buenos Aires). Membro da Academia Nacional de Historia (Argentina).
} 


\section{INTRODUÇÃO}

Se o que se pretende fazer é História do Direito, resulta necessário deter-se a refletir previamente sobre o que compreende na realidade o direito pretérito. Vale dizer, determinar no que consistiu. Contudo, esse direito do passado - como também o do presente, diga-se de passagem - não se reduz a mera normatividade. Trata-se de algo mais complexo. Definitivamente, expressa uma cultura. Ou seja, o que o âmbito jurídico compreende é um conjunto compartido de conhecimentos, valores, princípios e ideologias que, vinculados ao Direito, imperam numa época e num lugar determinados ${ }^{1}$. Feito esse primeiro esclarecimento, também devemos advertir outra coisa. Referimo-nos a uma dimensão que se deixa transparecer nas palavras com as quais o mestre Ricardo Zorraquín Becú chamou à atenção sobre o caráter heterogêneo da normativa americana ${ }^{2}$. Trata-se do fato de que a lei indiana dos dois primeiros séculos da Coroa castelhana na América não foi a nossa lei. Isso significa que não se enquadrou nos padrões racionalistas de abstração, uniformidade e imperatividade, próprios da Modernidade $^{3}$. Assentado esse marco referencial, antecipamos que o que se pretende fazer a seguir é tornar compreensível ao leitor contemporâneo o sentido e o alcance das leis de Índias durante os primeiros duzentos anos da dominação castelhana. E por que razão não se ocupar do período bourbônico? Porque, durante o citado período, a lei transitou por rumos diferentes, aproximando-se bastante ao que atualmente entendemos como tal ${ }^{4}$. Cabe esclarecer, ademais, que, dada a inexistência de uma explicação formal de época, nossa tentativa de desencriptar o passado àquilo que apontamos é para recriar uma mais ou menos rudimentar "teoria" da lei indiana. Em busca desse objetivo, recorremos, principalmente, à consulta direta de algumas expressões normativas contidas na Recopilación de Leyes de los Reinos de Indias, de 1680, e à consulta de duas consagradas expressões doutrinárias de meados do século XVII. Referimonos à Política Indiana, de Juan de Solórzano y Pereira ${ }^{\text {a }}$ - publicada primeiramente em 1647 -,

\footnotetext{
${ }^{1}$ Cf.: ABÁSOLO, Ezequiel. Bastante más que 'degradantes andrajos de nuestra pasada esclavitud': fragmentos sudamericanos de la pervivencia de la cultura jurídica indiana durante el siglo XIX. Buenos Aires: Instituto de Investigaciones de Historia del Derecho, 2014. p. 136.

2 ZORRAQUíN BECÚ, Ricardo. El sistema de fuentes en el derecho indiano. Anuario Histórico Jurídico Ecuatoriano, vol. VI, p. 03, 1980.

${ }^{3}$ Eduardo Martiré destaca essa condição em sua obra: MARTIRÉ, Eduardo. Las Audiencias y la Administración de Justicia en las Indias. Madrid: Universidad Autónoma de Madrid, 2005. p. 33.

${ }^{4}$ Ver, a esse respeito, o que digo na obra: ABÁSOLO, Ezequiel. Animado Yo de los mismos deseos de mi Augusto Padre: estudios y documentos sobre la fijación del derecho de la Monarquía española durante la época de Carlos IV. Buenos Aires: Instituto de Investigaciones de Historia del Derecho, 2009. (passim).

${ }^{a}$ Nota de tradução: a edição utilizada neste texto é a seguinte: SOLÓRZANO Y PEREIRA, Juan de. Política Indiana. t. 1-2. Madrid: Matheo Sacristán, e Imprenta Real de la Gazeta, 1736-1776.
} 
e ao Govierno Eclesiástico Pacífico, de Gaspar de Villaroel ${ }^{\text {b }}$ - publicado inicialmente em 1656. Pois bem, quanto ao que faz as leis, esclarecemos que aqui não se distinguirá entre as diferentes modalidades textuais possíveis, como pragmáticas, leis em sentido estrito, ordenanças ou cédulas reais ${ }^{5}$. Limitamo-nos a considerar como tais os mandatos assinados pelo Rei, ou, eventualmente, pelos integrantes de seu Conselho para o governo do Novo Mundo. Ou seja, que tomaremos o conjunto de diversas cédulas e ordens dispostas como "em forma de leis", às quais se referia o jovem Solórzano ${ }^{6}$. Quanto ao papel assumido pelo dicastério aludido, tenhase presente também que, como derivação da atribuição de competências sobre os negócios das Índias que "delas resultassem e dependessem" - conforme afirma a segunda das Ordenanzas aprovadas em 1571, incorporada em seguida à Recopilación de Leyes de los Reinos de Indias de 1680 como lei 2, título 2, livro 2 - "para a boa governação delas, e administração de justiça", este Conselho contava com atribuições para ordenar, e fazer, com consulta à Real pessoa, as leis, pragmáticas, ordenanças e provisões gerais e particulares, "que por tempo para o bem daquela república conviessem" 7 .

\section{IMPLICAÇÕES DA PRESENÇA DO IUS COMMUNE}

Enquanto que, tal como já antecipamos supra, a legislação hispano-americana dos séculos XVI e XVII somente pode ser compreendida quando emoldurada nos cânones da cultura jurídica de seu tempo, não devemos perder de vista que, mediante a adesão aos padrões e critérios de um onipresente ius commune ${ }^{8}$, o direito indiano se caracterizou, principalmente: (a) pela primazia de uma concepção técnica casuísta, atenta às manifestações concretas sensíveis das sociedades americanas; (b) pela admissão de um cenário policêntrico de potestades normativas; e (c) por um regime de fontes formais que não pretendia estruturar-se rigidamente e antecipadamente, de onde se presumiria como algo normal que, em cada ocasião

\footnotetext{
${ }^{\mathrm{b}}$ Nota de tradução: o autor utiliza a seguinte edição dessa obra: VILLARROEL, Gaspar de. Govierno eclesiástico pacífico, y unión de los dos cuchillos pontificio, y regio. t. II. Madrid: Oficina de Antonio Marín, 1738.

${ }^{5}$ Sobre a variedade de expressões normativas que compreende a genérica referência a leis, ver: GARCÍA-GALLO, Alfonso. La ley como fuente del derecho en Indias en el siglo XVI. Anuario de Historia del Derecho Español, $\mathrm{t}$. XXI-XXII, p. 618, 1951-1952.

${ }^{6}$ Cf. o memorial dirigido ao Rei por Juan de Solórzano y Pereira, datado de 8 de abril de 1618. Transcrito na obra: ALTAMIRA, Rafael. El primer proyecto de Recopilación de Indias, hecho por D. Juan de Solórzano Pereyra. Bulletin Hispanique, t. 42, n. 2, p. 105, 1940.

${ }^{7}$ Ver também: SOLÓRZANO Y PEREIRA, Juan de. Política Indiana. cit.: libro V, cap. XVI, § 1, p. 401.

${ }^{8}$ MARILUZ URQUIJO, José María. Ius commune y Nuevo Mundo. In: CONDORELLI, O. [ed.]. Panta rei: Studi dedicati a Manlio Bellomo. Roma: Il Cigno Edizioni, 2004. p. 513.
} 


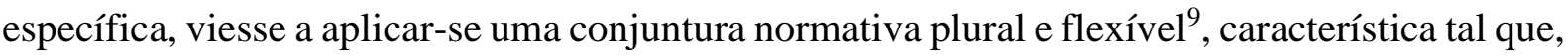
conforme feliz imagem do memorável professor António Manuel Hespanha, resultava numa "geometria variável" 10 .

Pois bem, se na legislação indiana confluíram importantes expressões prescritivas, isso não significa necessariamente que elas tivessem sido concebidas para aplicar-se com critério imperativo. Pelo contrário, e como acertadamente o advertiu em seu momento Alfonso GarcíaGallo, era mais próprio da diferente natureza dessas leis dos séculos XVI e XVII, quanto às atuais, o persuadir e o convencer, antes do exigir ${ }^{11}$. Disso se deduz, por exemplo, que um Solórzano viesse a reprovar - enquanto manifestação de um pretenso "mau estilo" - que as normas legais ordenassem a seu cumprimento com palavras "ásperas" e "severas" ${ }^{2}$. Tampouco se pode perder de vista que, não poucas vezes, o desenho normativo se reduzia, simplesmente, a orientar os funcionários a adotar um certo caminho, e não muito mais. Tal classe de prescrições conferia aos obrigados a cumpri-las com a liberdade suficiente para fazer com o ordenado como "lhes parecesse" e fosse conveniente ${ }^{13}$.

Recordemos, também, que os enunciados legais indianos se articulavam de acordo com uma textura aberta ${ }^{14}$. Consequentemente, seu entendimento somente se tornava compreensível em vista da intervenção de alguns operadores jurídicos que se debruçavam sobre eles conforme as orientações do ius commune ${ }^{15}$. Do afirmado anteriormente resulta que, para poder chegar à autêntica compreensão destas leis, requer-se bastante mais que sua mera leitura individual. Em termos efetivos, "entender" as leis indianas supunha integrá-las a um variado conjunto de expressões normativas, não somente civis, mas também canônicas. Sem pretensão de enumerá-

\footnotetext{
${ }^{9}$ ABÁSOLO, Ezequiel. Bastante más que 'degradantes andrajos de nuestra pasada esclavitud': fragmentos sudamericanos de la pervivencia de la cultura jurídica indiana durante el siglo XIX. Buenos Aires: Instituto de Investigaciones de Historia del Derecho, 2014. p. 162.

${ }^{10}$ HESPANHA, António Manuel. Porque é que existe e em que é que consiste um direito colonial brasileiro. Quaderni Fiorentini per la storia del pensiero giuridico moderno, n. 35, t. I, p. 70, 2006.

${ }^{11}$ GARCÍA-GALLO, Alfonso. La ley como fuente del derecho en Indias en el siglo XVI. Anuario de Historia del Derecho Español, t. XXI-XXII, p. 671, 1951-1952.

${ }^{12}$ SOLÓRZANO Y PEREIRA, Juan de. Política Indiana. t. 1-2. Madrid: Matheo Sacristán, e Imprenta Real de la Gazeta, 1736-1776: libro V, cap. XVI, § 25, p. 407.

${ }^{13}$ Ver, como um exemplo dentre muitos outros possíveis, deste tipo de mandatos, o texto da lei 6, título 4, livro 3 , da Recopilación de Leyes de los Reinos de Indias, ditada por Felipe II em 1563, e relativa aos espanhóis desobedientes. Antecipo que estas cláusulas - às quais podemos identificar genericamente com a expressão "como mejor pareciere" - ainda não têm sido detidamente estudadas. Pretendemos ocupar-nos delas em outro trabalho específico.

${ }^{14}$ TAU ANZOÁTEGUI, Víctor. Casuismo y sistema: indagación histórica sobre el espíritu del Derecho Indiano. Buenos Aires: Instituto de Investigaciones de Historia del Derecho, 1992. p. 316.

${ }^{15}$ A respeito deste, ver: BARRIENTOS GRANDÓN, Javier. Historia del Derecho Indiano. Del descubrimiento colombino a la codificación. I. Ius Commune - Ius Proprium en las Indias Occidentales. Roma: Il Cigno Galileo Galilei, 2000. p. 283.
} 
las todas, entre elas caberia ter em conta a opinio doctorum, sustentada na literatura profissional e sintetizada em uma variedade de brocardos; o arbítrio judicial; o costume; os "exemplares"; e uma pluralidade de critérios teológicos e morais ${ }^{16}$. Além disso, no momento de enfrentar a sua aplicação funcional, os enunciados legais indianos voltavam a desnudar a sua falta de autonomia e sua insuficiência estrutural. Isso era assim porque, quando postos em prática, complementavam-se com a epiqueia - a qual não deve ser traduzida sem mais como equidade, mas, tal como a Real Academia espanhola continua defendendo em nossos dias, como uma “interpretação moderada e prudente da lei, segundo as circunstâncias de tempo, lugar e pessoa". Desse modo, as leis somente alcançavam um sentido operativo pleno uma vez "aperfeiçoadas" mediante a intervenção dessa epiqueia, a partir da qual sofriam uma verdadeira metamorfose. Definitivamente, e como resultado das aludidas interações com elementos externos, os enunciados legais adquiriam algumas dimensões normativas às quais não resultaria possível que fossem assim inferidas, isso a partir de uma leitura restrita ao conteúdo que unicamente contemplavam em seus textos ${ }^{17}$.

Tenhamos presente agora que a capacidade de legislar - onde importava adentrar em "matérias graves de governo", para proporcionar-lhe "seus olhos" à "República", e "maior defesa e proveito que as armas" 18 - era ponderada por Solórzano como algo "concernente às supremas e maiores Regalias dos Príncipes, Reis e Imperadores" ${ }^{19}$. Conforme Villarroel, de sua parte, não se poderia discutir que os príncipes contavam com atribuições para fazer normas civis, nem o fato de que as cédulas reais fossem "verdadeiras leis", comparadas "às Epístolas, ou Reescritos dos Imperadores Romanos" ${ }^{20}$. Não obstante, o reconhecimento destas competências na pessoa do príncipe não supunha consagrar uma liberdade ilimitada para encarar o desenho normativo. E ainda que, durante os séculos XVI e XVII, resulte perceptível o paulatino incremento das pretensões legiferantes régias, o certo é que durante esse período

\footnotetext{
${ }^{16}$ TAU ANZOÁTEGUI, Víctor. La noción de ley en América hispana durante los siglos XVI a XVIII. In: TAU ANZOÁTEGUI, Víctor. La ley en América Hispana: del descubrimiento a la emancipación. Buenos Aires: Academia Nacional de la Historia, 1992. p. 32.

${ }^{17}$ Sobre esta dimensão, chama à atenção com agudeza: CUENA BOY, Francisco. Teoría y práctica de la ley. Apuntes sobre tres juristas indianos. Cuadernos de Historia del Derecho, n. 13, p. 19, 2006.

${ }^{18}$ Cf. SOLÓRZANO Y PEREIRA, Juan de. Política Indiana. t. 1-2. Madrid: Matheo Sacristán, e Imprenta Real de la Gazeta, 1736-1776: libro V, cap. XVI, § 8, 19 e 28, p. 402, 405 e 407. Ley 2, tít. II, libro II, Recopilación de Leyes de los Reinos de Indias.

${ }^{19}$ SOLÓRZANO Y PEREIRA, Juan de. Política Indiana. t. 1-2. Madrid: Matheo Sacristán, e Imprenta Real de la Gazeta, 1736-1776: libro V, cap. XVI, § 2, p. 401.

${ }^{20}$ VILLARROEL, Gaspar de. Govierno eclesiástico pacífico, y unión de los dos cuchillos pontificio, y regio. t. II. Madrid: Oficina de Antonio Marín, 1738: t. II, n. 25 e 42, p. 72 e 75.
} 
ainda nos encontraríamos muito distantes de um exercício legislativo de caráter absoluto ${ }^{21}$. No mote do explica, Alfonso García-Gallo demonstrava que as exposições de motivos das leis indianas não respondiam a uma exigência de estilo, nem eram uma mera formalidade, senão que constituíam “partes essenciais da lei”, enquanto justificavam ante os súditos a oportunidade e necessidade dos mandatos legais ${ }^{22}$. De outra parte e enquanto o sustento da força normativa das leis continuasse se direcionando à autoridade, antes que ao imperium $^{23}$, instava-se aos governantes que afrontassem o ditado da legislação "com muito acordo e deliberação", de onde:

estando primeiro muito informados e certificados do que antes foi provido nas matérias sobre as quais houverem de dispor, e precedendo à maior notícia e informação que se possa das coisas e negócios, e das partes para onde se provenham, com informação e parecer dos que governarem, ou puderem dar delas alguma luz, se na dilação de pedir informação, não houver algum inconveniente ${ }^{24}$.

Nesta ordem de coisas, Solórzano recomendava ademais que, à hora de desenhar e aplicar as leis, os governantes tivessem em conta "o que é lícito, segundo a razão, e justiça, e o que será decente, e bem parecido conforme à honestidade, e conveniente, e expediente à pública utilidade, [por]que nem todas as leis podem adaptar-se a todas Nações, e Regiões" ${ }^{25}$. Em termos definitivos, pois, as leis deveriam ser expressão acabada da prudência ${ }^{26}$.

Ademais, durante nossa época, o reconhecimento da força normativa das leis ainda continuava dependendo de sua justiça intrínseca ${ }^{27}$. Como também de sua adequação a uma poderosa ordem normativa superior, indisponível ao legislador régio. A julgar por estes critérios, com alguns séculos de antecipação à experiência colombina, Alfonso, o Sábio ${ }^{\mathrm{c}}$, já se havia referido à perda de vigência de uma norma régia por opor-se à lei de Deus ou ao "direito senhorio"; por dar-se de bruços com o "pro comunal da terra"; ou por colidir com alguma

\footnotetext{
${ }^{21}$ TAU ANZOÁTEGUI, Víctor. La noción de ley en América hispana durante los siglos XVI a XVIII. In: TAU ANZOÁTEGUI, Víctor. La ley en América Hispana: del descubrimiento a la emancipación. Buenos Aires: Academia Nacional de la Historia, 1992. p. 38 e 39.

${ }^{22}$ GARCÍA-GALLO, Alfonso. La ley como fuente del derecho en Indias en el siglo XVI. Anuario de Historia del Derecho Español, t. XXI-XXII, p. 670, 1951-1952.

${ }^{23}$ Remete-se a esta ideia em: SOLÓRZANO Y PEREIRA, Juan de. Política Indiana. t. 1-2. Madrid: Matheo Sacristán, e Imprenta Real de la Gazeta, 1736-1776: libro V, cap. XVI, § 20, p. 405.

${ }^{24}$ Recopilación de Leyes de Indias, ley 12, título 2, libro 2.

${ }^{25}$ SOLÓRZANO Y PEREIRA, Juan de. Política Indiana. cit.: libro V, cap. XVI, § 18, p. 405.

${ }^{26}$ Ibidem: libro V, cap. XVI, § 4, 17 e 21, p. 402 e 405

${ }^{27}$ GARCÍA-GALLO, Alfonso. La ley como fuente del derecho en Indias en el siglo XVI. Anuario de Historia del Derecho Español, t. XXI-XXII, p. 671, 1951-1952.

${ }^{\mathrm{c}}$ Nota de tradução: a edição da renomada obra do rei Alfonso, o Sábio, adotada no texto original deste artigo é a seguinte: Los códigos españoles concordados y anotados. t. 2, Código de las Siete Partidas. Madrid: La Publicidad, 1848 .
} 
"bondade conhecida" 28 . Por sua vez, conforme Solórzano as leis se faziam "comendáveis, e respeitáveis, pela razão em que se fundamentam", desautorizando-as "quem - não somente insistindo na extensão presumida de suas palavras, mas também na curteza do expressamente disposto por ela - obra contra o que pede sua intenção e vontade" ${ }^{29}$. Atendendo a considerações análogas, o corpo normativo alfonsino preconizava nesta ordem de coisas que, antes de ditar as leis, o Rei consultasse elevados operadores jurídicos, e "aos melhores homens que pudesse haver, e de mais terras, porque sejam muitos de acordo", de onde o Direito, "quanto mais acordado é, e mais examinado, tanto melhor é, e mais firme" ${ }^{30}$. Além disso, os juristas indianos consideravam que, na ponderação da legislação, deveria ter-se em conta "a vontade do povo", algo muito em concordância com o que sustentara durante o século II o jurista romano Sálvio Juliano - em uma reflexão sua, posteriormente incorporada ao Digesto de Justiniano como número 32, título III, livro I -, de onde "por nenhuma outra causa" as leis obrigavam ${ }^{31}$.

\section{AS LEIS JUSTAS E AJUSTADAS}

Em sua complexa trama, resultava que o tecido normativo indiano se entretecia em torno de uma pluralidade de soluções casuístas e particulares, que evocavam as aspirações de um mundo alheio à rigidez legal da Modernidade. Assim, enquanto para Juan de Solórzano y Pereira, as leis não eram aptas para "compreender todos os casos e pontos, que oferece sua prática" ${ }^{32}$, para Gaspar de Villarroel, dava-se "assento a sentença de Doutores, quando se há de conformar a lei com o tempo, com a condição do súdito, com as circunstâncias, e as ocasiões, e com os humores da Região" ${ }^{33}$. Em concordância com isso, por aqueles dias se tinha como factualmente impossível uma lei "que em tudo se ajuste, e seja uniforme a todo o gênero humano" ${ }^{34}$. Em sentido semelhante viria a manifestar-se, dentre outros, o Vice-Rei peruano Francisco de Toledo, ao assegurar a Felipe II que, sendo "a terra, costumes, temperamento, e

\footnotetext{
${ }^{28}$ Los códigos españoles concordados y anotados. t. 2, Código de las Siete Partidas. Madrid: La Publicidad, 1848: ley 18 , título 1 , libro I.

${ }^{29}$ SOLÓRZANO Y PEREIRA, Juan de. Política Indiana. t. 1-2. Madrid: Matheo Sacristán, e Imprenta Real de la Gazeta, 1736-1776: libro III, cap. XXIII, § 27, p. 355.

${ }^{30}$ Los códigos españoles concordados y anotados. t. 2, Código de las Siete Partidas. Madrid: La Publicidad, 1848 : ley 17 , título 1 , libro I.

${ }^{31}$ Francisco Cuena Boy recorda a remissão ao pensamento de Sálvio Juliano por parte de Frei Miguel - ver: CUENA BOY, Francisco. Teoría y práctica de la ley. Apuntes sobre tres juristas indianos. Cuadernos de Historia del Derecho, n. 13, p. 15, 2006.

${ }^{32}$ SOLÓRZANO Y PEREIRA, Juan de. Política Indiana. cit.: libro III, cap. XX, n. 22, p. 338.

${ }_{33}$ VILLARROEL, Gaspar de. Govierno eclesiástico pacífico, y unión de los dos cuchillos pontificio, y regio. t. II. Madrid: Oficina de Antonio Marín, 1738: t. II, parte II, q. XII, art. IV, n. 80, p. 79.

${ }^{34}$ SOLÓRZANO Y PEREIRA, Juan de. Política Indiana. cit.: libro V, cap. XVI, § 3, p. 402.
} 
nações e províncias" do distrito a seu encargo "tão variadas", não era "possível que, pela ordem de uma lei ou ordenança se possam todas governar, porque o que a uns fosse muito proveitoso, a outros será danoso" ${ }^{35}$. Este sentimento comum, que replicava velhas características da sensibilidade jurídica medieval, desponta, por exemplo, nas concepções de um Solórzano, quem - ao mesmo tempo em que pregava que os magistrados deveriam julgar mediante leis escritas, permanecendo "atados a elas, e que somente em coisas de pouca consideração, e importância se lhes deixe livre o arbítrio" 36 -, mantinha sua adesão ao ideal conforme o qual era melhor "o bom Rei, que a boa lei" ${ }^{37}$. Com esse panorama como pano de fundo, entende-se por que razão durante os séculos XVI e XVII se assumisse que as leis, ademais de justas, deveriam ser ajustadas $^{38}$. Consequentemente, instava-se a que a legislação satisfizesse o que "fora pedindo o tempo, e a utilidade, e conveniência daquelas Províncias, e Repúblicas", e se tinha por altamente provável que "aquilo que hoje se estabeleceu de forma salutar", viesse a resultar conveniente "mudar amanhã" ${ }^{39}$. Na mesma toada desse tipo de perspectiva, para o Frei Gaspar de Villarroel, de Quito, resultava simplesmente inconcebível "que neste Novo Mundo seja firme, e fixo o governo, e que as leis humanas sejam duradouras: porque sobre ser tão inúmeros os casos particulares, a cujo remédio assistem as leis, é o homem animal tão variado, que hoje lhe turva a saúde a medicina que a sanava ontem" ${ }^{40}$. Assim sendo, entende-se como e por que se impôs nas Índias o particularismo normativo. A esse respeito, enquanto se admitia como normal que toda sociedade contasse com legislação própria, alcançou a condição de critério dominante que as Américas viessem a requer urgentemente de uma normativa específica:

porque tudo, ou o mais, é novo nelas, ou digno de inovar-se a cada dia, sem que nenhum direito, fora do natural, possa ter firmeza, e consistência, nem os costumes, e exemplos que achamos introduzidos sejam dignos de se continuar, nem as leis de Roma, ou Espanha, se adaptem ao que pede a variedade de seus naturais, além de outras mudanças, e variedades, que cada dia ocasionam os inopinados sucessos, e repentinos acidentes que sobrevêm ${ }^{41}$.

\footnotetext{
${ }^{35}$ Carta de Francisco de Toledo, datada em Los Reyes em 8 de fevereiro de 1570. Disponível em: LEVILLIER, Roberto. Gobernantes del Perú: Cartas y papeles. Siglo XVI. Documentos del Archivo de Indias. t. III. Madrid: Sucesores de Rivadeneyra, 1921. p. 353. (Colección de Publicaciones Históricas de la Biblioteca del Congreso Argentino)

${ }^{36}$ Ibid., $\S 8$, p. 402.

${ }^{37}$ SOLÓRZANO Y PEREIRA, Juan de. Política Indiana. t. 1-2. Madrid: Matheo Sacristán, e Imprenta Real de la Gazeta, 1736-1776: libro V, cap. XVI, § 6, p. 402.

${ }^{38}$ SOLÓRZANO Y PEREIRA, Juan de. Política Indiana. cit.: libro V, cap. XVI, § 11, p. 403.

${ }^{39}$ Ibidem: libro V, cap. XVI, § 3, p. 402.

${ }^{40}$ VILLARROEL, Gaspar de. Govierno eclesiástico pacífico, y unión de los dos cuchillos pontificio, y regio. t. II. Madrid: Oficina de Antonio Marín, 1738: t. II, parte II, q. XII, art. IV, n. 14, p. 71.

${ }^{41}$ SOLÓRZANO Y PEREIRA, Juan de Política Indiana. cit.: libro V, cap. XVI, § 4, p. 402.
} 
Constituía lugar comum, pois, reconhecer que os casos novos e mutáveis eram “inumeráveis, e [que] o que hoje importa à conservação de um Reino, pode prejudicá-lo amanhã, e mudar as leis ... quando importa, não é inconstância" ${ }^{42}$. Sobre esse último particular, o mestre Mariluz Urquijo explica que, a princípio, a atitude dos indianos era de não as substituir, isso enquanto fossem consequências de "situações estáveis, decantadas com o correr do tempo" ${ }^{43}$, princípio do qual derivava o ter por característica própria de um mau governante o "fazer a cada passo uma lei" ${ }^{44}$. Não obstante, também se admitia que, à medida que fosse necessário, a variação normativa não deveria ter por inconstância, mas por providência ${ }^{45}$.

\section{CONCLUSÃO}

Digamos, por fim, que casuísmo e particularismo indianos respondiam a uma matriz comum de pensamento normativo tópico. Entretanto, não compreendiam nem abarcavam exatamente o mesmo. Ao calor do casuísmo, que resolvia com bastante acerto os desafios propostos por uma sociedade simultaneamente estamental e mutável, o que se ofereciam eram soluções próprias de uma ordem normativa móvel, em permanente construção e reconstrução. Para explicar a sua essência, Solórzano acudiu a uma fábula sobre a lua - previamente cunhada pelo clérigo inglês Edward Weston ${ }^{46}$-, conforme a qual o astro noturno "pediu a sua mãe um vestido" ao que esta se negou, "[terminando] por dizer que, como perpetuamente mudava de tamanho, não sabia de que medida se lhe poderia fazer, [uma vez] que se enquadrava com tantas formas" ${ }^{47}$. O particularismo, por sua parte, ainda que também se dirigisse a satisfazer o desafio de situações que não eram iguais entre si, não se preocupava no que se refere ao circunstancial e momentâneo. O que pretendia era oferecer uma resposta a outro tipo de diferenças, mais ou menos permanentes e estruturais, derivadas, em sua maior parte, da variável geografia

\footnotetext{
${ }^{42}$ VILLARROEL, Gaspar de. Govierno eclesiástico pacífico, y unión de los dos cuchillos pontificio, y regio. t. II. Madrid: Oficina de Antonio Marín, 1738: t. II, parte II, q. XII, art. IV, n. 66, p. 77.

${ }^{43}$ MARILUZ URQUIJO, José María. El concepto de tierra nueva en la fundamentación de la peculiaridad indiana. In: Memoria del IV Congreso del Instituto Internacional de Historia del Derecho Indiano. México: Universidad Nacional Autónoma de México, 1976. p. 330.

${ }^{44}$ VILLARROEL, Gaspar de. Govierno eclesiástico pacífico, y unión de los dos cuchillos pontificio, y regio. cit.: t. II, parte II, q. XII, art. IV, n. 4, p. 70.

${ }^{45}$ Ibid., n. 71, p. 78.

${ }^{46}$ WESTONO LONDINENSI, Edovardo. Theatrum vitae civilis ac sacrae sive de moribus republicae christianae comentaria in quinque libros distributa. Amberes: Gulielmum Tongris, 1626: livro 4, capítulo 12, n. 3, p. 413.

${ }^{47}$ SOLÓRZANO Y PEREIRA, Juan de. Política Indiana. t. 1-2. Madrid: Matheo Sacristán, e Imprenta Real de la Gazeta, 1736-1776: libro V, cap. XVI, § 5, p. 402.
} 
continental. O reconhecimento destas especiais circunstâncias se plasmou em fórmulas alusivas à qualidade e à novidade da terra ${ }^{48}$.

\section{FONTES}

Los códigos españoles concordados y anotados. t. 2, Código de las Siete Partidas. Madrid: La Publicidad, 1848.

LEVILLIER, Roberto. Gobernantes del Perú: Cartas y papeles. Siglo XVI. Documentos del Archivo de Indias. t. III. Madrid: Sucesores de Rivadeneyra, 1921. (Colección de Publicaciones Históricas de la Biblioteca del Congreso Argentino).

Recopilación de leyes de los Reynos de Indias. Prólogo por Ramón Menéndez y Pidal. Estudio preliminar de Juan Manzano Manzano. Madrid: Ediciones Cultura Hispanica, 1973.

SOLÓRZANO Y PEREIRA, Juan de. Política Indiana. t. 1-2. Madrid: Matheo Sacristán, e Imprenta Real de la Gazeta, 1736-1776.

VILLARROEL, Gaspar de. Govierno eclesiástico pacífico, y unión de los dos cuchillos pontificio, y regio. t. II. Madrid: Oficina de Antonio Marín, 1738.

WESTONO LONDINENSI, Edovardo. Theatrum vitae civilis ac sacrae sive de moribus republicae christianae comentaria in quinque libros distributa. Amberes: Gulielmum Tongris, 1626.

\section{REFERÊNCIAS BIBLIOGRÁFICAS}

ABÁSOLO, Ezequiel. Animado Yo de los mismos deseos de mi Augusto Padre: estudios y documentos sobre la fijación del derecho de la Monarquía española durante la época de Carlos IV. Buenos Aires: Instituto de Investigaciones de Historia del Derecho, 2009.

ABÁSOLO, Ezequiel. Bastante más que 'degradantes andrajos de nuestra pasada esclavitud': fragmentos sudamericanos de la pervivencia de la cultura jurídica indiana durante el siglo XIX. Buenos Aires: Instituto de Investigaciones de Historia del Derecho, 2014.

ALTAMIRA, Rafael. El primer proyecto de Recopilación de Indias, hecho por D. Juan de Solórzano Pereyra. Bulletin Hispanique, t. 42, n. 2, 1940.

BARRIENTOS GRANDÓN, Javier. Historia del Derecho Indiano. Del descubrimiento colombino a la codificación. I. Ius Commune - Ius Proprium en las Indias Occidentales. Roma: Il Cigno Galileo Galilei, 2000.

\footnotetext{
${ }^{48}$ Cf.: MARILUZ URQUIJO, José María. El concepto de tierra nueva en la fundamentación de la peculiaridad indiana. In: Memoria del IV Congreso del Instituto Internacional de Historia del Derecho Indiano. México: Universidad Nacional Autónoma de México, 1976. p. 330. Também se debruça sobre esta categoria, adicionando valiosas contribuições: BARRIERA, Darío. La tierra nueva es algo libre y vidriosa. El delito de 'traición a la coronal real': lealtades, tiranía, delito y pecado en jurisdicción de la Real Audiencia de Charcas (1580-1581). Ley, Razón y Justicia - Revista de Investigación en Ciencias Jurídicas y Sociales, a. 8, n. 11, jul. 2006/mar. 2010, p. 283 et seq.
} 
BARRIERA, Darío. La tierra nueva es algo libre y vidriosa. El delito de 'traición a la coronal real': lealtades, tiranía, delito y pecado en jurisdicción de la Real Audiencia de Charcas (15801581). Ley, Razón y Justicia - Revista de Investigación en Ciencias Jurídicas y Sociales, a. 8, n. 11, jul. 2006/mar. 2010.

CUENA BOY, Francisco. Teoría y práctica de la ley. Apuntes sobre tres juristas indianos. Cuadernos de Historia del Derecho, n. 13, 2006.

GARCÍA-GALLO, Alfonso. La ley como fuente del derecho en Indias en el siglo XVI. Anuario de Historia del Derecho Español, t. XXI-XXII, 1951-1952.

HESPANHA, António Manuel. Porque é que existe e em que é que consiste um direito colonial brasileiro. Quaderni Fiorentini per la storia del pensiero giuridico moderno, n. 35, t. I, 2006.

MARILUZ URQUIJO, José María. Ius commune y Nuevo Mundo. In: CONDORELLI, O. [ed.]. Panta rei: Studi dedicati a Manlio Bellomo. Roma: Il Cigno Edizioni, 2004.

MARILUZ URQUIJO, José María. El concepto de tierra nueva en la fundamentación de la peculiaridad indiana. In: Memoria del IV Congreso del Instituto Internacional de Historia del Derecho Indiano. México: Universidad Nacional Autónoma de México, 1976.

MARTIRÉ, Eduardo. Las Audiencias y la Administración de Justicia en las Indias. Madrid: Universidad Autónoma de Madrid, 2005.

TAU ANZOÁTEGUI, Víctor. Casuismo y sistema: indagación histórica sobre el espíritu del Derecho Indiano. Buenos Aires: Instituto de Investigaciones de Historia del Derecho, 1992.

TAU ANZOÁTEGUI, Víctor. La noción de ley en América hispana durante los siglos XVI a XVIII. In: TAU ANZOÁTEGUI, Víctor. La ley en América Hispana: del descubrimiento a la emancipación. Buenos Aires: Academia Nacional de la Historia, 1992.

ZORRAQUÍN BECÚ, Ricardo. El sistema de fuentes en el derecho indiano. Anuario Histórico Jurídico Ecuatoriano, vol. VI, 1980.

\section{DADOS DA PUBLICAÇÃO}

Categoria: artigo de autor convidado.

Recebido em: 20/09/2021.

Aceito em: 13/12/2021. 